\title{
EthniC Fractionalization, GOVERNANCE AND LOAN DEFAULTS IN AFRICA*
}

\author{
Svetlana Adrianova, University of Leicester \\ Badi H. Baltagi, Syracuse University and University of Leicester \\ Panicos Demetriades, University of Leicester \\ David Fielding, University of Otago
}

Address for correspondence:

Name David Fielding

Department of Economics

University of Otago

PO Box 56

Dunedin

NEW ZEALAND

Email: david.fielding@otago.ac.nz

Telephone: 6434798653

\footnotetext{
* We would like to acknowledge the support of ESRC-DFID grant number $\mathrm{ES} / \mathrm{J} 009067 / 1$.
} 


\title{
EthniC Fractionalization, Governance AND LOAN DeFAults IN AFRICA*
}

\author{
Svetlana Adrianova, University of Leicester \\ Badi H. Baltagi, Syracuse University and University of Leicester \\ Panicos Demetriades, University of Leicester \\ David Fielding, University of Otago
}

\begin{abstract}
We present a theoretical model of moral hazard and adverse selection in an imperfectly competitive loans market that is suitable for application to Africa. The model allows for variation in both the level of contract enforcement (depending on the quality of governance) and the degree of market segmentation (depending on the level of ethnic fractionalization). The model predicts a specific form of non-linearity in the effects of these variables on the loan default rate. Empirical analysis using African panel data for 111 individual banks in 29 countries over 2000-2008 provides strong evidence for these predictions. Our results have important implications for the conditions under which policy reform will enhance financial development.
\end{abstract}

KEYWORDS: Ethnic fractionalization, Governance, Financial development, African Banks, Panel data.

JEL CLASSIFICATION: G21, O16

\footnotetext{
* We would like to acknowledge the support of ESRC-DFID grant number ES/J009067/1.
} 


\section{Introduction}

In terms of financial development, Africa still lags behind other parts of the world. African banks are deterred from lending in domestic markets by a lack of creditworthy borrowers, and loan volumes are highly sensitive to default rates (Adrianova et al., 2014). As a result, many African banks are excessively liquid and channel an unusually large proportion of domestic savings abroad, although there is substantial variation in banks' default risk and asset structure, both within and between countries (Honohan and Beck, 2007). At the same time, firm and household surveys reveal endemic credit constraints. For this reason, understanding the determinants of the rate of loan default is crucial in overcoming obstacles to financial development in Africa. Our paper makes a first step in this direction by providing both theory and evidence that shed new light on the factors behind the high rate of loan default in many parts of Africa.

The focus of attention in both the theoretical and empirical parts of the paper is on two key characteristics of the African banking sector. Firstly, there is great deal of variability across Africa in terms of both the level of corruption and the quality of contract enforcement. This variability is revealed in indices of the quality of governance produced by organisations such as the World Bank, Transparency International, and the Bureau van Dijk. Daumont et al. (2004) argue that weak contract enforcement in Africa is due to a number of factors, including excessively time-consuming and unwieldy legal procedures, high litigation costs, a lack of appropriately qualified judges, and inadequacies in the cadastral system that inhibit the identification of collateral property. The large variation in the magnitude of these problems across Africa suggests that they may help explain the observed variation in the incidence of loan default. Secondly, many African counties are characterized by a high level of ethnic fractionalization (Easterly and Levine, 1997). A lack of trust between different ethnic 
groups is likely to generate high inter-ethnic transactions costs, which will lead to a high level of market segmentation (Aker et al., 2010; Robinson, 2013). Existing studies of ethnic market segmentation have not focused explicitly on financial markets, but there is no reason to suppose that financial markets are any less susceptible to this problem than others. Even in countries with a large banking sector, ethnic fractionalization is likely to create monopolistic competition, because banks are differentiated by the ethnicity of their staff. African banks are therefore likely to face unusually inelastic demand curves.

The theoretical section of the paper develops a model of loan default which emphasizes the importance of imperfect competition and the quality of governance. This model features both adverse selection and moral hazard, problems which are exacerbated when market segmentation is more pronounced or when the quality of contract enforcement is poor. Unsurprisingly, the theory predicts that high loan default rates are more likely when there is greater market segmentation or when contract enforcement is weak. But the model also produces some less obvious predictions about non-linearities in these effects that arise from the interaction of the market segmentation and contract enforcement problems. Improvements in the quality of contract enforcement will reduce loan default rates only in certain situations: specifically, when the contract enforcement problem is initially neither much more severe nor much less severe than the market segmentation problem. The theory can help explain why in some circumstances improvements in enforcement quality have a large effect on loan default rates, but in other circumstances there may be little or no effect. The empirical section of the paper tests the predictions of the theoretical model using a panel data set on loan default rates faced by individual African banks. In the empirical model, market segmentation is interpreted in terms of ethnic fractionalization and contract enforcement is interpreted in terms of the quality of governance as measured by the World Bank's World Governance Indicators. We find strong evidence to support 
the predictions of the theoretical model, which has important implications for financial development policy.

\section{Theory}

Our starting point is a Hotelling (1929) 'linear city' model that embodies a degree of product differentiation between banks whose financial services are imperfectly substitutable. ${ }^{1}$ There are three different types of entrepreneur who seek a loan of one dollar in order to undertake an investment project: 'honest' borrowers (in proportion $\alpha$ ), 'dishonest' borrowers (in proportion $\beta$ ) and 'opportunistic' borrowers (in proportion $\gamma$, with $\alpha+\beta+\gamma=1$ ). The honest type of borrower has an investment project with a return of $R$ dollars, and this borrower always repays the loan. The opportunistic type of borrower has the same investment project (with a return $R$ ), but can choose whether to repay or default on the loan. The dishonest type of borrower has a project with rate of return equal to zero, and this borrower will always default on the loan. The borrower's type is private information, but the proportions $\alpha, \beta$ and $\gamma$ are publicly known.

All borrowers are uniformly distributed along a unit interval with a distribution density equal to one. Each borrower can apply for a loan from at most one bank. There

1 Some of the features of our model are shared with other models that extend the credit rationing theory of Stiglitz and Weiss (1981). For example, Besanko and Thakor (1987), Petersen and Rajan (1995) and Hoff and Stiglitz (1998) develop theories of adverse selection and /or moral hazard in a monopolistic competition setting. However, the banks in these models have market power because of features such as increasing returns to scale, not product differentiation. Villas-Boas and Schmidt-Mohr (1999) and Hauswald and Marquez (2006) do present models that allow for product differentiation, but these models focus on adverse selection rather than moral hazard, and do not allow for the variation in the quality of contract enforcement that is central to our model. The model presented here is an extension of the one in Andrianova et al. (2014), and, unlike that model, incorporates asymmetric information on both sides of the transaction. 
are two banks, which are located at opposite ends of the interval. The banks compete for loan contracts, with bank $i(i \in\{A, B\})$ setting its loan interest rate $r_{i}$ to maximise its expected payoff. Applying for a loan is costly to a borrower because of a 'transportation' cost of $t$ dollars per unit of distance between the borrower and the bank. One interpretation of the distance between the banks is that it represents an ethnic difference. For example, each of the two banks could be associated with a different tribe, with the customers coming from a variety of tribes that are culturally closer either to one bank's tribe or to the other's. In this interpretation, $t$ is a measure of the cost that accompanies interactions with other tribes. In general, we might expect $t$ to be larger in countries that are more ethnically diverse and in which the unit interval in the model represents a greater cultural divide. In this way, $t$ parameterizes the magnitude of the market segmentation problem discussed in the introduction.

Each bank has sufficient funds to approve all loan applications (which is consistent with the findings of Honohan and Beck, 2007). The banks differ in their ability to gather and use information about an individual borrower's characteristics. ${ }^{2}$ Either bank can be of one of the two types: a 'competent' type with a screening technology or an 'incompetent' type with no ability to screen borrowers. The bank is competent with probability $\kappa$ and incompetent with probability $1-\kappa$. The value of $\kappa$ is common knowledge, but only the bank itself knows which type it is. If the borrower is opportunistic or dishonest, then with probability $\sigma$ the screening technology reveals this information. With probability $1-\sigma$ the screening fails to reveal any information. With

\footnotetext{
2 This assumption can be justified by noting that in the presence of 'connected lending' those banks with connections to the political (or industrial) elite may intentionally approve loans to politically connected borrowers regardless of any adverse information that is available or can be gathered through screening.
} 
slight abuse of notation, we assume that a $\kappa$-type bank chooses whether to screen or not to screen, and then whether to refuse or not to refuse applications from borrowers with a negative screening signal. Both banks have access to a safe asset with a return equal to $r_{0}\left(0<r_{0}<R\right)$.

Loan contract enforcement is imperfect. When a loan has funded a project with a return of $R$, default on the loan is penalized with probability $\lambda$; the penalty is equal to $1+R$ dollars, of which the bank receives $1+r_{i}$ dollars. In other words, if the bank is compensated then it receives the amount stipulated in the loan contract. With probability $1-\lambda$ no contract enforcement is possible and there is no penalty. When the loan has funded a project with a zero return, no enforcement of the loan contract is ever possible.

The return on the investment is observable ex post and is non-falsifiable. All players are risk-neutral. The timing of events is as follows:

(1) Bank i sets its lending rate $r_{i}$.

(2) Each borrower chooses a bank to apply for a loan of one dollar.

(3) Facing a demand for loans equal to $D_{i}$, bank $i$ chooses whether to screen all of its loan applications or not. This choice will depend on whether it is a $\kappa$-type bank.

(4) Each bank chooses which applications to approve and which to decline.

(5) Honest and opportunistic borrowers with an approved loan invest the money.

(6) An honest borrower repays the loan, a dishonest borrower defaults, and an opportunistic borrower chooses whether to repay or to default.

(7) In the case of default, the banks seek compensation. 
(8) Payoffs are realized.

Let $q \in\{0,1\}$ denote an opportunistic borrower's decision whether to repay $(q=1)$ or to default $(q=0)$. Let $\xi \in\{0,1\}$ be a $\kappa$-type bank's decision to screen, with $\xi=1$ in the case of screening. Let $p_{j} \in\{0,1\}$, where $j \in\{\kappa, 1-\kappa\}$, be a $j$-type bank's decision whether to approve all of its applications when there is no screening. Note that if the transportation cost $t$ is too high then no-one will want to apply for a loan. Also, if the proportion of dishonest borrowers $(1-\alpha)$ is negligible then a competent bank will find it unprofitable to use the screening technology. In what follows, we assume that $t$ and $\alpha$ are low enough so there is a market for loans and the screening technology is relevant. Solving the model backwards for pooling equilibria, we obtain the following result:

Proposition 1. There exist values $\underline{\lambda}, \bar{\lambda}, \bar{\beta}$ and $\bar{t}$ so that for $\beta \geq \bar{\beta}$ and $t \leq \bar{t}$, the unique equilibrium of the model is:

(i) The low default equilibrium (LDE) with $q=\xi=p_{1-\kappa}=1$, when $\lambda \geq \bar{\lambda}$.

(ii) The high default equilibrium (HDE) with $q=0$ and $\xi=p_{1-\kappa}=1$, when $\underline{\lambda} \leq \lambda<\bar{\lambda}$.

(iii) The no lending equilibrium (NLE) with $q=\xi=p_{\kappa}=p_{1-\kappa}=0$, when $\lambda<\underline{\lambda}$

More details are given in Appendix A. Intuitively, the NLE occurs when contract enforcement is very weak. In such a situation, widespread default by opportunistic and dishonest borrowers makes lending unprofitable for any screening technology. Since we do observe some bank lending, even in countries with very weak institutions, the NLE is 
probably of theoretical interest only. The LDE occurs when there is a non-negligible proportion of dishonest borrowers but contract enforcement is sufficiently good. The HDE occurs within an intermediate range of contract enforcement parameter values, when opportunistic borrowers have no incentive to repay (given relatively weak enforcement) but the banks nevertheless find it profitable to screen and to lend to all borrowers for whom no negative signal has been obtained. (This equilibrium requires contract enforcement not to be too weak and default compensated often enough to make lending profitable.) Note that for all equilibria, both banks set the same interest rate: $r_{A}$ $=r_{B}$.

In Appendix $\mathrm{A}$ we derive an equation for $\bar{\lambda}$ which takes the following form:

$\bar{\lambda}=\frac{1+r_{i}}{1+R}, \quad r_{i}=r_{A}=r_{B}$

Equation (1) defines the minimal value of $\lambda$ required for the market to be in the LDE: below this value, the HDE will obtain. Appendix A also includes an equation for the interest rate in the LDE:

$1+r_{i}=\frac{t}{\alpha+(1-\kappa \sigma) \gamma}-\frac{(\beta+\gamma)\left(1+r_{0}\right) \sigma}{\alpha+(1-\sigma) \gamma}$

Combining equations (1-2) we have:

$\bar{\lambda}=\left[\frac{1}{1+R}\right]\left[\frac{t}{\alpha+(1-\kappa \sigma) \gamma}-\frac{(\beta+\gamma)\left(1+r_{0}\right) \sigma}{\alpha+(1-\sigma) \gamma}\right]$ 
The two key country characteristics that we will be analyzing in the next section are the quality of governance (interpreted in our theoretical model as $\lambda$ ) and the magnitude of ethnic fractionalization (which we interpret as a correlate of the 'transportation' cost $t$ ). Equation (3) implies that in $(\lambda, t)$ space the LDE-HDE boundary will be an upwardsloping line, as shown in Figure I. Higher values of $t$ push up the boundary value of $\lambda$ : a higher level of 'transportation' costs gives more local monopoly power to the banks and pushes up the equilibrium interest rate; this makes opportunistic borrowers more likely to default at the margin, so better contract enforcement is required to maintain the LDE equilibrium.

Figure I exactly describes a country in which all investment projects yield the same return $R$. In such a country, small changes in $\lambda$ or $t$ will have no effect on the default rate unless the starting point is very close to the boundary line. If the starting point is close to the boundary line, then a small change could take the country across the line, with a very large change in the default rate. In reality, however, different investors are likely to face different returns: for example, returns could vary from one part of the country to another. If each bank is lending in a variety of regional markets, each market with its own $R$-value, then a different boundary line will be associated with each market. There will be a distribution of boundary lines, as illustrated by the gray area in Figure II. Outside of the gray area, small changes in $\lambda$ or $t$ will still have no effect on the overall default rate for a bank, but inside the area there will be some effect, as the boundary line is crossed for some value of $R$. If the $R$-values are unimodally distributed, then the magnitude of the effect of a small change in $\lambda$ or $t$ will be greater when the starting point is closer to the modal boundary line (the black line in Figure II). In other words, the response of the overall default rate to a small change in $\lambda$ 
or $t$ will be smaller when the starting point is further from the modal boundary line, i.e. when either $\lambda$ is high and $t$ is low, or $\lambda$ is low and $t$ is high.

This brings us to a set of specific empirical predictions about the relationship between the default rate, governance and ethnic fractionalization across countries and over time. Firstly, as long as some countries in some time periods fall within the gray area in Figure II, we should see a negative correlation between the default rate and $\lambda$ (governance), since a higher value of $\lambda$ moves a country upwards towards the LDE space; we should see a positive correlation between the default rate and $t$ (ethnic fractionalization), since a higher value of $t$ moves a country rightwards towards the HDE space. These predictions are unremarkable, but we should also see that the size of the effects is greater in countries / time periods where there is either (i) relatively poor governance and relatively low fractionalization (the south-west of Figure II) or (ii) relatively good governance and relatively high fractionalization (the north-east of Figure II). To put it another way, the level of governance at which changes in governance matter depends on the level of fractionalization: the higher the level of fractionalization, the higher the level of governance at which there will be the most sensitivity of the default rate. In the next section we test this prediction using cross-country panel data.

\section{Evidence}

In this section we present tests of the predictions outlined above, using African panel data for 111 individual banks in 29 countries over 2000-2008 to fit a model of the loan default rate of each bank. Our predictions relate to the relationship between the default rate which a bank faces and the conditions of the market in which it operates, primarily the quality of governance and the level of ethnic fractionalization in the country. Our three key empirical variables are as follows: 
(i) The default rate for bank $i$ in year $y$ (default $\left.t_{i y}\right)$, measured as the ratio of impaired loans to total loans. The loans data are collated from the Bankscope database published by the Bureau van Dijk (https://bankscope.bvdinfo.com).

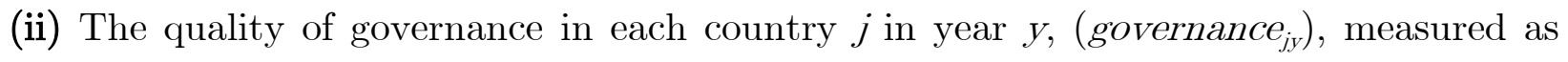
the first principal component of the following three variables in the World Bank's World Governance Indicators (WGI) database (http://info.worldbank.org/governance/wgi/): control of corruption, rule of law and regulatory quality. Control of corruption measures 'the extent to which public power is exercised for private gain, including both petty and grand forms of corruption, as well as "capture" of the state by elites and private interests.' Rule of law measures 'the extent to which agents have confidence in and abide by the rules of society, and in particular the quality of contract enforcement, property rights, the police, and the courts, as well as the likelihood of crime and violence.' Regulatory quality measures 'the ability of the government to formulate and implement sound policies and regulations that permit and promote private sector development.' Further discussion of the construction of these variables appears in Kaufmann et al. (2009); we interpret each of the variables as a measure of some of the factors driving the probability $(\lambda)$ that a bank will be able to enforce a loan contract if necessary. The variables are highly correlated in our sample, so it is not feasible to include more than one of them in any one model. ${ }^{3}$ Nevertheless, we will also explore the sensitivity of our results to the way in which $\lambda$ is measured by comparing the results

\footnotetext{
${ }^{3}$ The correlation coefficients are 0.93 for control of corruption and rule of law, 0.82 for control of corruption and regulatory quality, and 0.86 for rule of law and regulatory quality. The weights in the first principal component are almost uniform: 0.58 for control of corruption, 0.59 for rule of law, and 0.56 for regulatory quality.
} 
using the principal component with results using any one of the three individual indicators instead.

(iii) The $\log$ of ethnic fractionalization in country $j\left(\right.$ ethnic $\left._{j}\right)$. This variable measures ethnic diversity using a Herfindahl index: ethnic $i_{j}=\ln \left(1-\sum_{k=1}^{k=K}\left(s_{j k}\right)^{2}\right)$, where $s_{j k}$ is the share of the $k^{\text {th }}$ ethnic group in the total population of country $j$. Figures are taken from Alesina et al. (2003). Countries with more fractionalization are expected to have a higher financial transactions cost $(t)$ on average.

Variables (i-iii) are the main variables of interest. However, our empirical model also includes a number of control variables. Firstly, in the theoretical model in section 2 there are two types of bank (competent and not competent), with competent banks facing a lower default rate because their screening is partially effective. In practice there are likely to be a variety of banks with different levels of competence, and the empirical model includes some bank characteristics that may be correlated with competence. These characteristics are all measured using Bankscope data.

(iv) The age of bank $i$ in year $y$, measured in years $\left(\right.$ age $\left._{i y}\right)$, plus $\left(\text { age }_{i y}\right)^{2}$. Older banks may have had time to acquire competence in the screening of customers, in which case we would expect the default rate to be decreasing in age. On the other hand, very new banks may have fewer informal connections with the political elite and come under less pressure to issue loans to customers of dubious creditworthiness, in which case we would expect the default rate to be increasing in age. 
(v) The size of bank $i$ in year $y$, measured by the logarithm of total bank assets $\left(\right.$ assets $_{i y}$ ), where asset values are expressed in 2005 US dollars. There may be economies of scale in screening, in which case the default rate should be decreasing in bank size.

(vi) The share of the government in ownership of bank $i$ in year $y$ (governmentownership ). Government-owned banks may make less effort to screen certain customers, either because of political patronage or because the government wishes to raise the volume of finance to investors, even at the expense of a high rate of default. In this case, the default rate should be increasing in the government ownership share.

In addition to these measures of bank-specific heterogeneity, the empirical model also includes two additional country-specific variables.

(vii) The rate of growth of country j's GDP between year $y-1$ and year $y$ (growthrate $_{j y}$ ), where GDP is measured in 2005 US dollars, as reported in the World Bank's World Development Indicators (http://data.worldbank.org/products/wdi). A higher growth rate may be associated with a relative abundance of investment opportunities and a lower overall default rate.

(viii) An indicator variable equal to one if country $j$ is in North Africa and zero otherwise (North-Africa $)$. The North African countries in our sample are Egypt, Morocco and Tunisia. Data presented by Honohan and Beck (2007) indicate that the banking sector in North Africa differs from that in Sub-Saharan Africa in a number of key respects: North Africa has lower interest margins and wider access to financial services, and more closely resembles the banking sector of OECD countries. The NorthAfrica variable is intended to capture this heterogeneity. 
Summary statistics for the variables in the model are given in Table 1, which also includes information about the distribution of banks across the 29 countries in our sample. Missing observations for some banks in some years mean that we have an unbalanced panel with 528 observations in total.

Our empirical model is designed to test hypotheses about the effect on banks' loan default rates of the quality of governance ( $\lambda$ in the theoretical model, governance in the empirics) and ethnic fractionalization ( $t$ in the theoretical model, ethnic in the empirics). The theory implies that the effects will be non-linear, but first of all we test whether governance and ethnic have any impact on default on average. In order to do this, we note first of all that the dependent variable is limited to the interval $[0,1]$. An appropriate estimator for this type of limited dependent variable in a panel has been developed by Papke and Wooldridge (2008). Our underlying model is assumed to be of the form:

$$
E\left[\text { default }_{i y}\right]=F\left(\begin{array}{l}
\eta_{i}+\varphi_{y}+\theta_{1} \cdot \text { governance }_{j y}+\theta_{2} \cdot \text { ethnic }_{j}+\theta_{3} \cdot \text { age }_{i y} \\
+\theta_{3} \cdot\left(\text { age }_{i y}\right)^{2}+\theta_{5} \cdot \text { assets }_{i y}+\theta_{6} \cdot \text { government-ownership }_{i y} \\
+\theta_{7} \cdot \text { growth-rate }_{j y}+\theta_{8} \cdot \text { North-Africa }_{j}
\end{array}\right), i \in j
$$

where $F($.$) is a cumulative density function, \eta_{i}$ is a bank random effect and $\varphi_{y}$ is a year fixed effect. Following Papke and Wooldridge, we can estimate the $\theta$ parameters in equation (4) using a pooled fractional logit (or probit) model of default conditional on the eight explanatory variables plus the year fixed effects. Consistent estimates of the parameters are obtained by maximizing the Bernoulli log-likelihood function using a generalized linear model (GLM). The results below are based on estimates using the 
GLM routine in Stata 12; we report results from the logit version of the model, but the probit results are very similar.

Table 2 reports the estimates of the $\theta$ parameters in equation (1). ${ }^{4}$ Column 1 of the table reports the parameter estimates in the model using the principal component of the three WGI variables as the measure of governance, while columns 2-4 report the estimates using the individual WGI variables instead. The table also includes the tratios for each parameter estimate, which are based on standard errors clustered at the bank level. Note that with a fractional logit model, the $\theta$ parameters in Table 2 are not equal to the partial derivatives of the default rate with respect to each explanatory variable. Therefore, the parameters do not necessarily indicate the relative importance of each variable for the default rate. Estimates of the partial derivatives will be discussed later, and at this point we discuss only the signs of the estimated effects.

In column 1, all of the estimated parameters are significantly different from zero at the $5 \%$ level, except for those on government-ownership and growth-rate. Ceteris paribus, smaller banks have significantly higher default rates than larger ones, and middle-aged banks have significantly lower default rates than the youngest and oldest banks: the quadratic term in age implies that the lowest default rate is when age $=56$ years. The non-monotonicity of the age effects may reflect the fact that that there is more than one channel through which age affects defaults rates, as suggested above. Column 1 also shows that high default rates can be mitigated by good governance and low ethnic fractionalization. Conditional on all of these effects, North African banks have higher default rates than banks in Sub-Saharan Africa: this effect was not anticipated and deserves further study. These results are also feature of the models in columns 2-4, except that ethnic is not quite significant when control of corruption is

\footnotetext{
${ }^{4}$ The year fixed effects are jointly significant at the $1 \%$ level. They are not reported in the table, but are available on request.
} 
used to measure governance, and regulatory quality is not quite significant when it is used to measure governance. Nevertheless, the measures of governance and ethnic fractionalization are jointly significant at the $5 \%$ level in all four versions of the Table 2 model, and the relevant parameters have the expected signs in all cases. This suggests that our empirical measures are relevant to the theoretical quantities $\lambda$ and $t$, and we now proceed to use these measures to test the predictions of the theoretical model about the interaction between the effects of governance and ethnic fractionalization.

The theory predicts that the sensitivity of the default rate to governance and ethnic fractionalization will be greater when either both of these characteristics are relatively high or both of these characteristics are relatively low, in the north-east and south-west of Figure II. Table 3 reports a test of this prediction based on estimates of the parameters in equation (4) for two sub-samples: (i) observations for which governance (as measured by the principal component) and ethnic are either both above their sample mean values or both below their sample mean values; (ii) observations for which either governance is above its sample mean value and ethnic is below its sample mean value, or vice versa. If the prediction of the theory is correct, then we can expect the absolute values of the $\theta_{1}$ and $\theta_{2}$ parameters to be greater in (i) than in (ii). Table 3 shows that this is indeed the case; moreover, the differences are jointly significant at the $1 \%$ level, and the $\theta_{1}$ and $\theta_{2}$ parameters in (ii) are insignificantly different from zero. In other words, marginal changes in the quality of governance (or in the level of ethnic fractionalization) have more impact on the default rate when both are relatively high or both are relatively low, closer to the dividing line in Figure II. ${ }^{5}$

\footnotetext{
${ }^{5}$ Another striking feature of Table 3 is that the effect of growth-rate on default is significantly positive in (i) and significantly negative in (ii). However, variations in the effect of economic growth are not part of our theoretical predictions, so we do not pursue the effect any further here.
} 
Given this significant difference, as predicted by the theoretical model, we can try to estimate how $\partial$ default/ $\partial$ governance and $\partial$ default/ $\partial$ ethnic vary across different points in Figure II. In order to do this, we need to parameterize the interaction between the governance and ethnic effects. With a large enough sample, one possible approach would be to fit a model that included additional terms in equation (4) of the form $\theta_{10} \cdot$ governance $\cdot \mid$ governance $-\theta_{12} \cdot$ ethnic $\mid+\theta_{11} \cdot$ ethnic $\cdot \mid$ governance $-\theta_{12} \cdot$ ethnic $\mid$. The parameters $\theta_{10}$ and $\theta_{11}$ would capture the speed with which $\partial$ default/ $\partial$ governance and $\partial$ default/2ethnic fall as we move away from the dividing line in Figure II, and the parameter $\theta_{12}$ would depend on the slope of this line. However, the addition of these terms makes the argument of $F($.$) in equation (4) non-linear, and, with just over 500$ observations, estimates of $\theta_{12}$ turn out to be very imprecise. A slightly more restrictive alternative is to set $\theta_{12}=1$ and fit the following model:

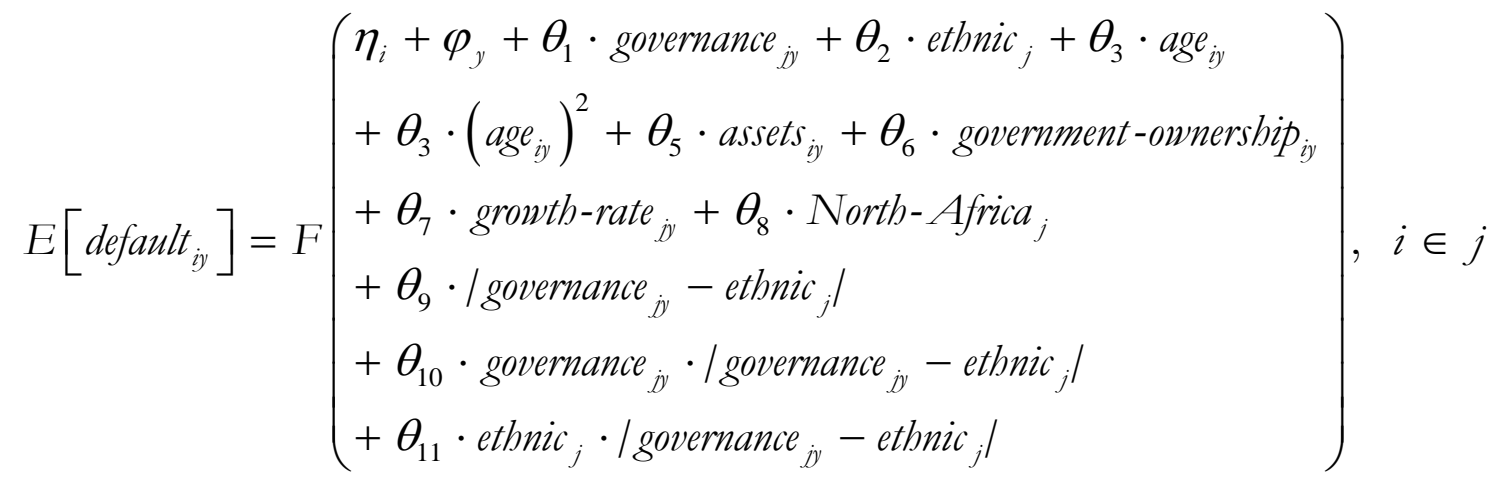

Note that the means and standard deviations of the WGI principal component and ethnic fractionalization variables in Table 1 are almost identical, so the results based on equation (5) would not be substantially different if standardized measures of these variables were used instead. Given the results in Table 3 , we can expect that $\theta_{1}<0<\theta_{2}$ and $\theta_{10}>0>\theta_{11}$ : larger absolute differences between the governance and ethnic 
fractionalization variables diminish the absolute size of the effect of both variables on the loan default rate.

Column 1 of Table 4 shows the estimates of the parameters in equation (5), along with the corresponding t-ratios. The signs of the four parameter estimates $\left(\theta_{1}, \theta_{2}, \theta_{10}\right.$, $\left.\theta_{11}\right)$ are consistent with our expectations, and other parameter estimates are similar to those in column 1 of Table 2, except that the government-ownership effect is somewhat larger and now significantly greater than zero: the default rates of government-owned banks are higher than those of privately owned ones. Columns 2-4 of Table 4 report results when the principal component is replaced by one or other of the individual WGI variables. Here, the $\theta_{1}$ and $\theta_{2}$ estimates are always significantly different from zero (which was not the case in Table 2), as are the estimate of $\theta_{10}$ when rule of law is used (column 3) and the estimates of $\theta_{11}$ when control of corruption or regulatory quality are used (columns 2 and 4). All significant parameter estimates have the expected sign. The log-likelihood in column 1 is higher than the log-likelihoods in the other columns, which indicates that using a combination of the WGI variables to measure governance captures somewhat more of the variation in default rates than using any one of the variables individually.

The results in column 1 of Table 4 can be used to calculate the average effect of each variable on the default rate, i.e. $\theta_{n} \cdot F^{\prime}$ evaluated at the mean value of default, $n=$ $1, \ldots, 11$. These effects are reported in Table 5, along with the corresponding t-ratios, which were computed using a bootstrap with 500 replications. This table shows that a $1 \%$ increase in the size of a bank (as measured by its asset base) reduces the default rate by about half a percentage point, and that a one percentage point increase in the share of the government in the bank's ownership increases the default rate by just over 0.1 percentage points. For a bank of average age (37 years), an extra year of age also raises 
the default rate by just over 0.1 percentage points. In order to interpret the effects of governance and ethnic fractionalization, note that the minimum value of |governance-ethnic| is 0.01 . At this value, when the | governance-ethnic | interaction terms are negligible, a unit improvement in either governance or ethnic fractionalization (in other words, a one standard deviation improvement, since the standard deviations of these variables are both close to one) reduces the default rate by about ten percentage points. Effects for larger values of $\mid$ governance - ethnic $\mid$ are shown in Figures III-IV: at the mean value of |governance - ethnic| (about 1.5), the effects of governance and ethnic fractionalization on the default rate are about half as large as at the minimum value; at values of |governance - ethnic| greater than about 2.5 the effects become insignificantly different from zero. Table 1 notes that the mean default rate is 0.11 and the standard deviation is 0.13 , so both the average effects of governance and ethnic fractionalization and the sensitivity of these effects to |governance - ethnic| are economically significant.

\section{Discussion}

The theoretical model presented in this paper shows that when a country's banking sector is characterized by market segmentation (which is one possible consequence of ethnic fractionalization), adverse selection and moral hazard, improvements in the quality of contract enforcement will sometimes - but not always reduce the incidence of loan default. When segmentation is acute, it is at high initial levels of contract enforcement quality that improvements in quality will make a difference; when segmentation is less severe, it is at low initial levels of contract enforcement quality that improvements in quality will make a difference. Analysis using African panel data for 111 individual banks in 29 countries over 2000-2008, provides support for these predictions. 
These results suggest that discussions of the economic consequences of ethnic fractionalization need to be nuanced. In the context of financial markets, increased fractionalization has deleterious consequences only in some circumstances: namely, when the level of fractionalization is initially high (in countries with strong institutions) or when the level of fractionalization is initially low (in countries with weak institutions). Among both the most fortunate countries (low fractionalization, strong institutions) and among the least fortunate ones (high fractionalization, weak institutions), moderate differences in the level of fractionalization will not matter.

Our results also complement the discovery of threshold effects in the financegrowth relationship (Rioja and Valev, 2004; Demetriades and Law, 2006). ${ }^{6}$ These authors find that financial development has a larger impact on growth in middle-income or high-income countries, and is less important in low-income countries. Our results suggest that in highly ethnically fractionalized countries with initially weak institutions, marginal improvements in the quality of these institutions are unlikely to lead to very much financial development. In these countries, development policy must first mitigate the market segmentation that arises from ethnic fractionalization before improvements in institutional quality can ameliorate financial market outcomes. Otherwise, development policy that focuses on financial market institutions is unlikely to be successful. This is a dimension of policy sequencing that has not previously been recognized.

\footnotetext{
${ }^{6}$ See also the survey by Murinde (2012).
} 


\section{REFERENCES}

Adrianova, Svetlana, Badi H. Baltagi, Panicos Demestriades, and David Fielding, "Why do African banks lend so little?" Oxford Bulletin of Economics and Statistics, forthcoming, 2014.

Aker, Jenny C., Michael W. Klein, Stephen A. O’Connell, and Muzhe Yang, “Are borders barriers? The impact of international and internal ethnic borders on agricultural markets in West Africa," Working Paper No. 208, Center for Global Development, 2010.

Alesina, Alberto, Arnaud Devleeschauwer, William Easterly, Sergio Kurlat, and Romain Wacziarg. "Fractionalization," Journal of Economic Growth, 8 (2003), 155-194.

Besanko, David, and Anjan V. Thakor. "Collateral and rationing: sorting equilibria in monopolistic and competitive credit markets," International Economic Review, 28 (1987), 671-689.

Roland, Daumont, Francoise Le Gall, and Francois Leroux, "Banking in Sub-Saharan Africa: What went wrong?” IMF Working Paper No. 04/55, 2004.

Demetriades, Panicos, and Siong Hook Law, "Finance, institutions and economic development," International Journal of Finance \& Economics, 11 (2006), 245-260.

Easterly, William, and Ross Levine. “Africa's growth tragedy: Policies and ethnic divisions," Quarterly Journal of Economics, 112 (1997), 1203-1250.

Hauswald, Robert, and Robert Marquez. "Competition and strategic information acquisition in credit markets," Review of Financial Studies, 19 (2006), 967-1000. 
Hoff, Karla, and Joseph E. Stiglitz. "Moneylenders and bankers: Price-increasing subsidies in a monopolistically competitive market," Journal of Development Economics, 55 (1998), 485-518.

Honohan, Patrick, and Thorsten Beck, Making Finance Work for Africa (Washington, DC: World Bank, 2007).

Hotelling, Harold, "Stability in competition," Economic Journal, 39 (1929), 41-57.

Kaufmann, Daniel, Aart Kraay, and Massimo Mastruzzi (2009) "Governance matters VIII: Aggregate and individual governance indicators 1996-2008," Policy Research Working Paper No. 4978, World Bank, 2009.

Murinde, Victor, "Financial development and economic growth: Global and African evidence," Journal of African Economies, 21 (supplement 1, 2012), i10-i56.

Papke, Leslie E., and Jeffrey M. Wooldridge, "Panel data methods for fractional response variables with an application to test pass rates," Journal of Econometrics, 145 (2008), 121-133.

Petersen, Mitchell A., and Raghuram G. Rajan, "The effect of credit market competition on lending relationships," Quarterly Journal of Economics, 110 (1995), 407-443.

Rioja, Felix, and Neven Valev, "Does one size fit all? A reexamination of the finance and growth relationship," Journal of Development economics, 74 (2004), 429-447.

Robinson, Amanda L. "Internal borders: ethnic diversity and market segmentation in Malawi," paper prepared for the Working Group in African Political Economy National Meeting, Massachusetts Institute of Technology, May 3-4, 2013. 
Stiglitz, Joseph E., and Andrew Weiss. "Credit rationing in markets with imperfect information," American Economic Review, 71 (1981), 393-410.

Villas-Boas, J. Miguel, and Udo Schmidt-Mohr, "Oligopoly with asymmetric information: Differentiation in credit markets," RAND Journal of Economics, 30 (1999), 375-396. 


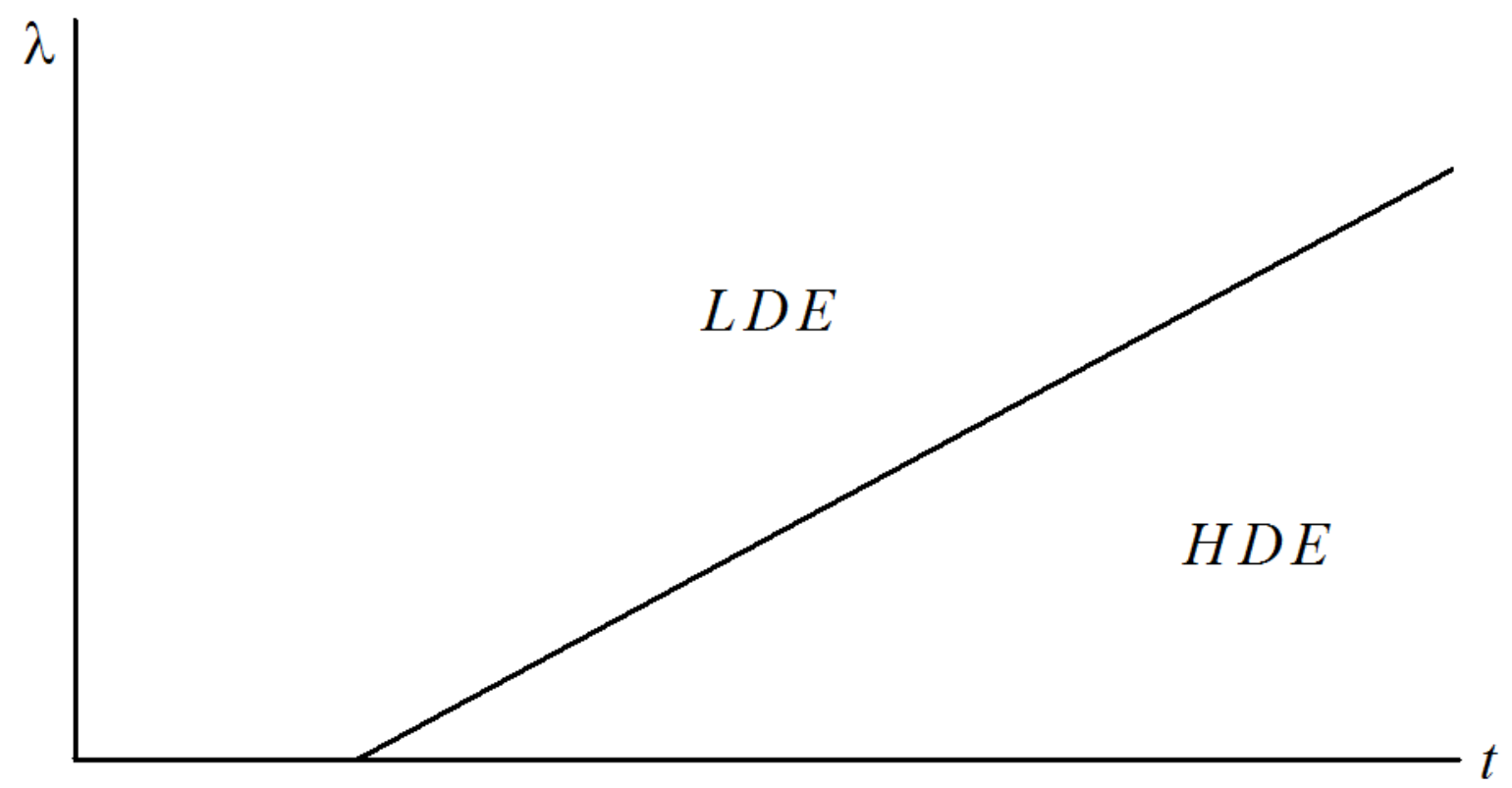

Figure I. - The Boundary Between the LDE AND HDE SPACES WITH HomogeneOUs InVESTMENT RETURNS

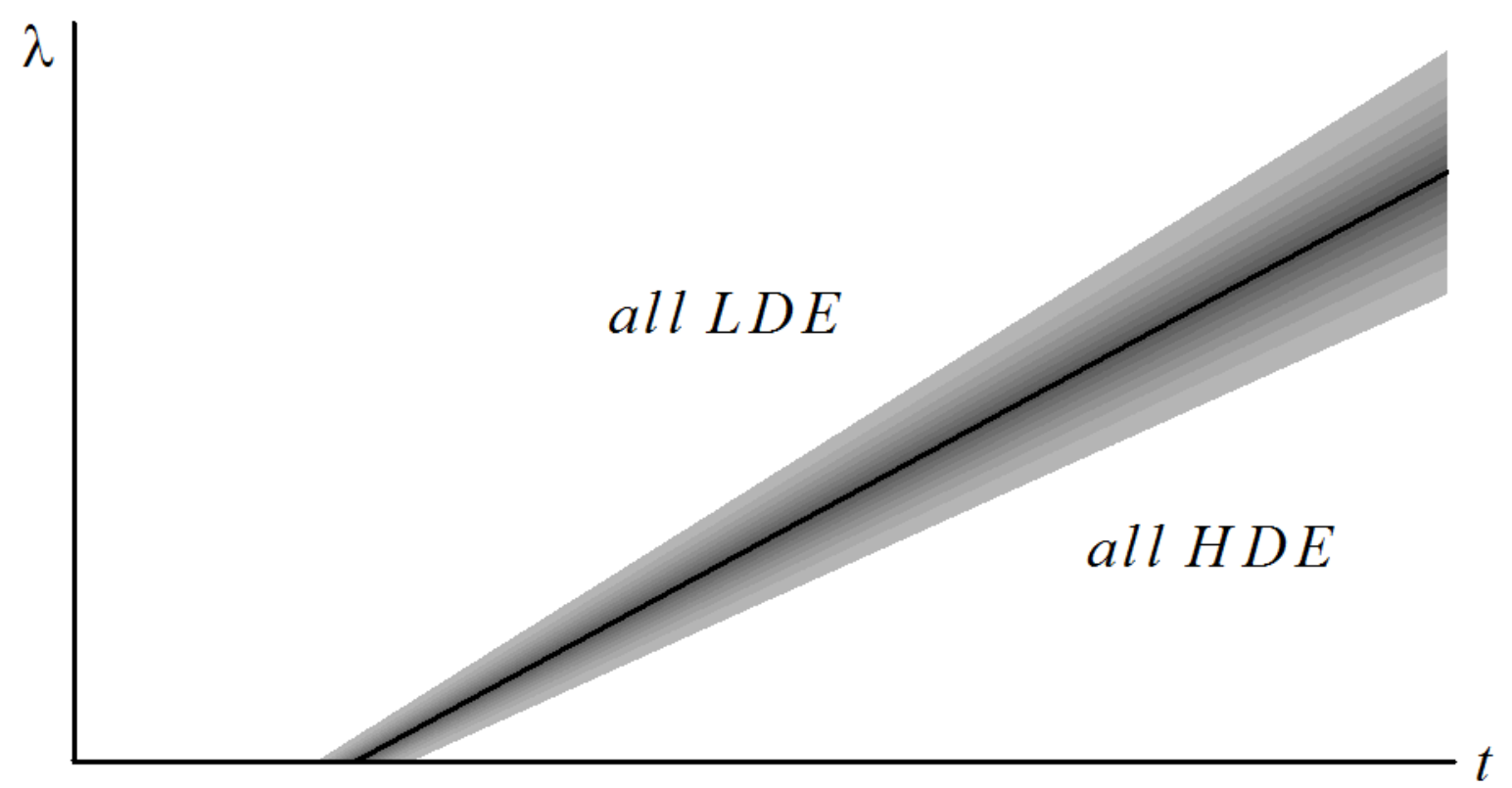

Figure II. - The Boundary Between the LDE And HDE SpaceS With Heterogeneous InVESTMEnt Returns 


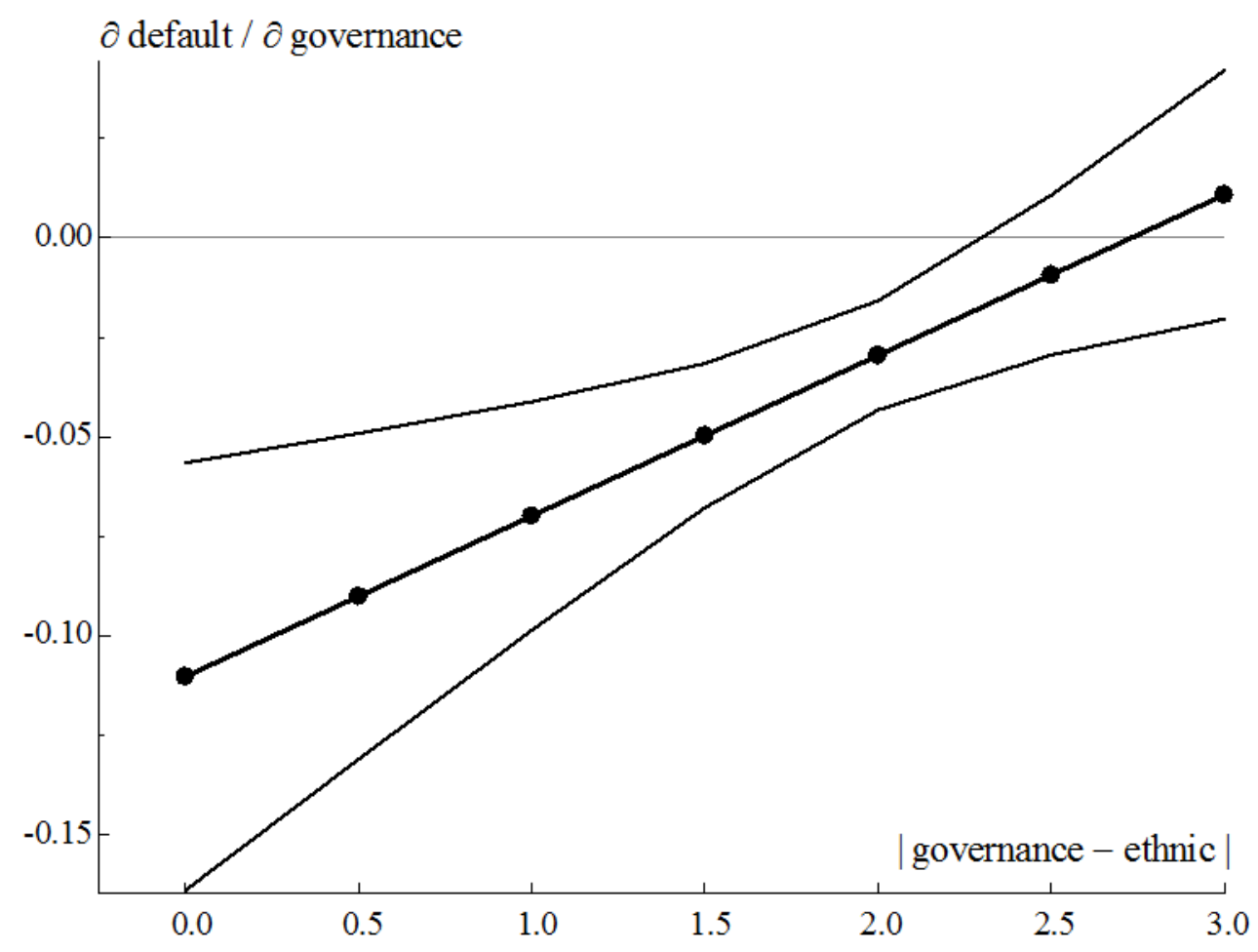

Figure III. - Average Partial EFfeCts For GOVERNANCE WITH 95\% CONFIDENCE BANDS

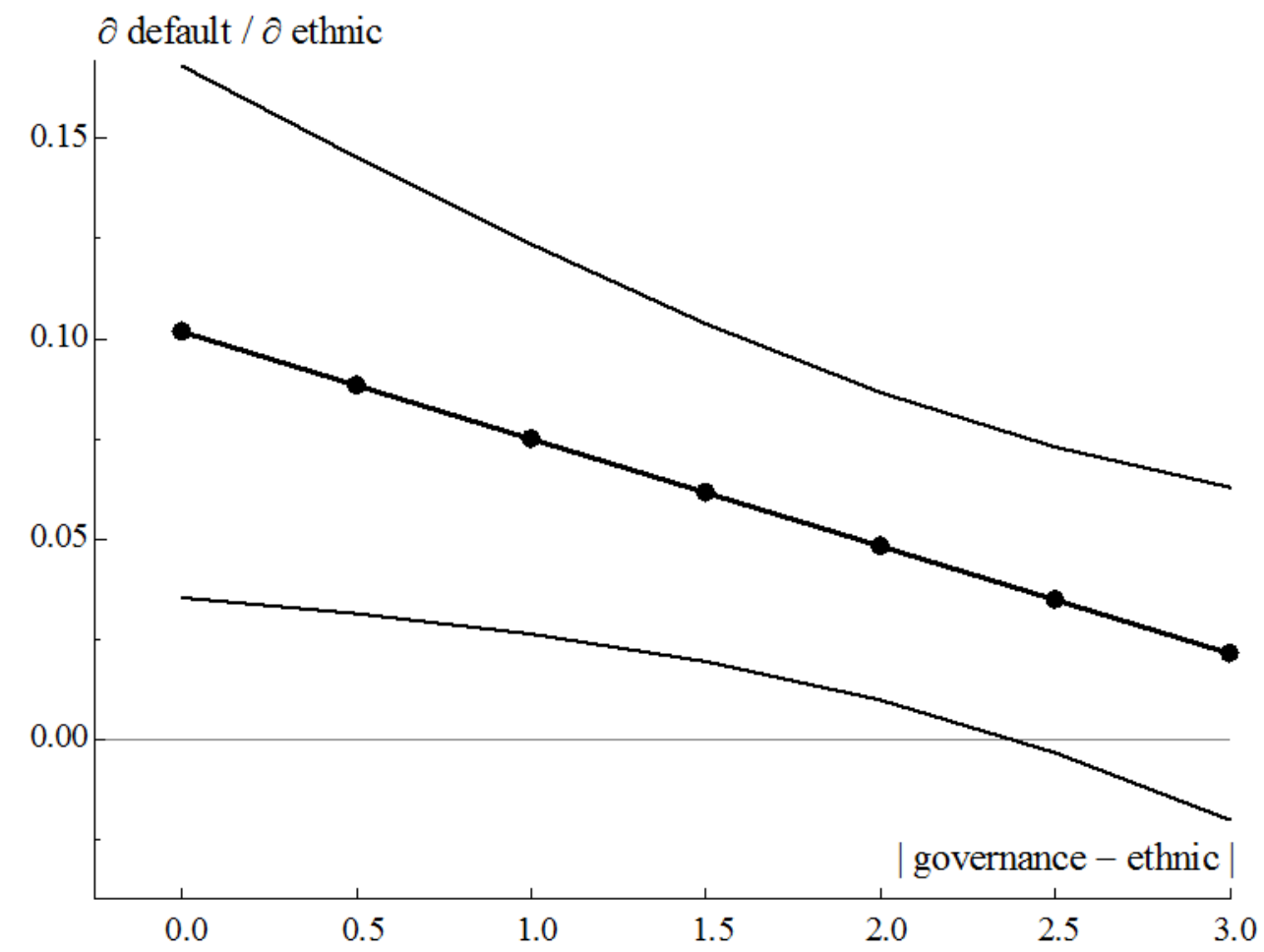

Figure IV. - Average Partial Effects for EThNiC With 95\% Confidence Bands 
TABLE 1. - Summary Statistics

(i) sample composition

banks observations

$\begin{array}{lrr}\text { Angola } & 2 & 12 \\ \text { Benin } & 3 & 19 \\ \text { Botswana } & 4 & 27 \\ \text { Cameroon } & 1 & 2 \\ \text { CAR } & 1 & 6 \\ \text { Chad } & 1 & 4 \\ \text { Egypt } & 4 & 18 \\ \text { Ethiopia } & 2 & 4 \\ \text { Gabon } & 1 & 4 \\ \text { Ghana } & 8 & 40 \\ \text { Kenya } & 14 & 80 \\ \text { Madagascar } & 1 & 4 \\ \text { Malawi } & 3 & 14 \\ \text { Mauritania } & 1 & 6 \\ \text { Mauritius } & 2 & 7\end{array}$

banks observations

2
9
2
6
4
8
4
4
40
80
4
4
6
7

(ii) distributions

mean std. dev. minimum maximum

default
age
assets
government-ownership
North-Africa
growth-rate
ethnic
governance:
$\quad$ principal component
$\quad$ control of corruption
$\quad$ rule of law
$\quad$ regulatory quality

0.1

37.1

7.54

0.08

0.15

0.04

$-0.89$

0.13

32.9

3.77

0.20

0.35

0.06

1.04

0.00

3.0

$-2.27$

0.00

0.00

$-0.19$

$-3.23$

$-0.86$

$-0.48$

$-0.55$

$-0.45$

$-3.08$

$0.65-1.55$

0.67

$-1.72$

0.74

$-2.37$
1.44

1.07

0.90

0.95 
TABLE 2. - Estimated Coefficients in the BAseline Model

\begin{tabular}{|c|c|c|c|c|c|c|c|c|}
\hline & \multicolumn{2}{|c|}{$\begin{array}{c}\text { 1. governance }= \\
\text { principal component }\end{array}$} & \multicolumn{2}{|c|}{$\begin{array}{c}\text { 2. governance }= \\
\text { control of corruption }\end{array}$} & \multicolumn{2}{|c|}{$\begin{array}{l}\text { 3. governance }= \\
\text { rule of law }\end{array}$} & \multicolumn{2}{|c|}{$\begin{array}{l}\text { 4. governance }= \\
\text { regulatory quality }\end{array}$} \\
\hline & coeff. & t-ratio & coeff. & t-ratio & coeff. & t-ratio & coeff. & t-ratio \\
\hline age $\div 100$ & 2.633 & 2.18 & 2.536 & 2.07 & 2.560 & 2.11 & 2.659 & 2.28 \\
\hline$(\text { age })^{2} \div 10,000$ & -2.370 & -2.40 & -2.291 & -2.28 & -2.329 & -2.34 & -2.376 & -2.53 \\
\hline assets $\div 100$ & -7.210 & -3.17 & -6.765 & -3.10 & -6.943 & -3.11 & -7.559 & -3.17 \\
\hline government-ownership & 0.841 & 1.53 & 0.849 & 1.51 & 0.895 & 1.64 & 0.786 & 1.48 \\
\hline North-Africa & 1.552 & 3.60 & 1.473 & 3.51 & 1.656 & 3.83 & 1.497 & 3.38 \\
\hline growth-rate & 0.977 & 0.77 & 0.855 & 0.69 & 0.842 & 0.68 & 0.490 & 0.36 \\
\hline governance & -0.244 & -3.40 & -0.573 & -4.55 & -0.478 & -3.89 & -0.177 & -1.38 \\
\hline ethnic & 0.280 & 2.02 & 0.194 & 1.48 & 0.277 & 2.03 & 0.337 & 2.32 \\
\hline log pseudo-likelihood & \multicolumn{2}{|c|}{-129.6} & \multicolumn{2}{|c|}{-128.8} & \multicolumn{2}{|c|}{-129.3} & \multicolumn{2}{|c|}{-130.5} \\
\hline sample size & \multicolumn{2}{|c|}{528} & \multicolumn{2}{|c|}{528} & \multicolumn{2}{|c|}{528} & \multicolumn{2}{|c|}{528} \\
\hline
\end{tabular}


TABLE 3. - Estimated Coefficients in the Model for Subsamples governance $=$ principal component

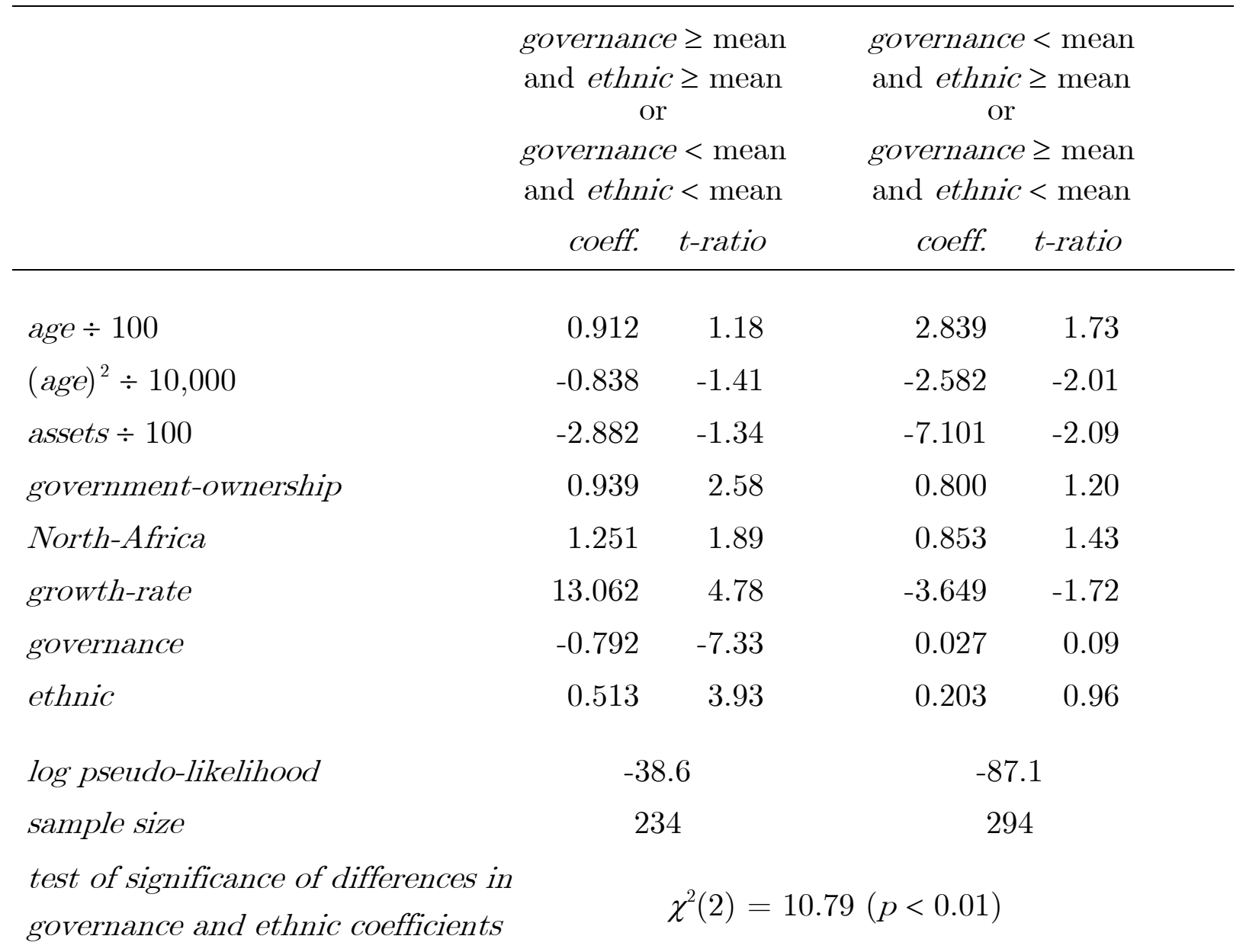


TABLE 4. - Estimated Coefficients in the Model with Interaction Terms

\begin{tabular}{|c|c|c|c|c|c|c|c|c|}
\hline & \multicolumn{2}{|c|}{$\begin{array}{l}\text { 1. governance }= \\
\text { principal component }\end{array}$} & \multicolumn{2}{|c|}{$\begin{array}{l}\text { 2. governance }= \\
\text { control of corruption }\end{array}$} & \multicolumn{2}{|c|}{$\begin{array}{l}\text { 3. governance }= \\
\text { rule of law }\end{array}$} & \multicolumn{2}{|c|}{$\begin{array}{l}\text { 4. governance }= \\
\text { regulatory quality }\end{array}$} \\
\hline & coeff. & t-ratio & coeff. & t-ratio & coeff. & t-ratio & coeff. & t-ratio \\
\hline age $\div 100$ & 2.193 & 1.91 & 2.485 & 2.11 & 2.375 & 2.06 & 2.320 & 2.02 \\
\hline$(\text { age })^{2} \div 10,000$ & -2.005 & -2.15 & -2.245 & -2.35 & -2.143 & -2.30 & -2.107 & -2.28 \\
\hline assets $\div 100$ & -5.837 & -3.07 & -5.071 & -2.60 & -5.973 & -3.06 & -5.207 & -2.78 \\
\hline government-ownership & 1.319 & 2.62 & 1.311 & 2.69 & 1.434 & 2.84 & 1.255 & 2.55 \\
\hline North-Africa & 1.489 & 2.49 & 1.603 & 2.95 & 1.546 & 2.22 & 1.609 & 2.64 \\
\hline growth-rate & 0.673 & 0.52 & -0.455 & -0.34 & 0.925 & 0.71 & 0.141 & 0.11 \\
\hline governance & -1.191 & -4.65 & -0.802 & -3.79 & -1.212 & -4.53 & -0.819 & -2.76 \\
\hline ethnic & 1.098 & 3.19 & 1.296 & 3.29 & 1.232 & 3.14 & 1.201 & 2.54 \\
\hline | governance - ethnic $\mid$ & -0.109 & -0.48 & -0.485 & -1.53 & -0.126 & -0.46 & -0.982 & -2.97 \\
\hline governance $\times \mid$ governance - ethnic $\mid$ & 0.436 & 2.94 & -0.005 & -0.03 & 0.520 & 2.50 & 0.273 & 1.06 \\
\hline ethnic $\times \mid$ governance - ethnic $\mid$ & -0.289 & -1.93 & -0.449 & -2.44 & -0.324 & -1.86 & -0.542 & -2.72 \\
\hline log pseudo-likelihood & \multicolumn{2}{|c|}{-126.3} & \multicolumn{2}{|c|}{-126.7} & \multicolumn{2}{|c|}{-126.7} & \multicolumn{2}{|c|}{-126.7} \\
\hline sample size & \multicolumn{2}{|c|}{528} & \multicolumn{2}{|c|}{528} & \multicolumn{2}{|c|}{528} & \multicolumn{2}{|c|}{528} \\
\hline
\end{tabular}


TABLE 5. - Average Partial Effects

IN THE Model With INTERACTION TERMS

$$
(\text { governance }=\text { principal component })
$$

\begin{tabular}{lrr}
\hline & coeff. & t-ratio \\
\hline age $\div 100$ & 0.203 & 2.11 \\
$(\text { age })^{2} \div 10,000$ & -0.186 & -2.19 \\
assets $\div 100$ & -0.541 & -3.17 \\
government-ownership & 0.122 & 2.91 \\
North-Africa & 0.138 & 2.62 \\
growth-rate & 0.062 & 0.73 \\
governance & -0.110 & -4.02 \\
ethnic & 0.102 & 3.00 \\
$\mid$ governance - ethnic $\mid$ & -0.011 & -0.58 \\
governance $\times \mid$ governance - ethnic $\mid$ & 0.040 & 2.97 \\
ethnic $\times \mid$ governance - ethnic $\mid$ & -0.027 & -2.19
\end{tabular}




\section{Appendix A: Derivation of Proposition 1}

In this derivation, we firstly set out the payoffs of all players and then establish the conditions which deliver the stated pooling equilibria. The expected payoff of a borrower of each type from applying for a loan to bank $i(i \in\{A, B\})$ is as follows:

$$
\begin{aligned}
U_{i}^{\alpha} & =\left[\kappa\left(\xi+(1-\xi) p_{\kappa}\right)+(1-\kappa) p_{1-\kappa}\right]\left[R-r_{i}\right]-t x_{i}^{\alpha} \\
U_{i}^{\beta} & =\left[\kappa\left(\xi(1-\sigma)+(1-\xi) p_{\kappa}\right)+(1-\kappa) p_{1-\kappa}\right]-t x_{i}^{\beta} \\
U_{i}^{\gamma} & =\left[\kappa\left(\xi(1-\sigma)+(1-\xi) p_{\kappa}\right)+(1-\kappa) p_{1-\kappa}\right] \\
& \times\left[(1+R)(1-\lambda(1-q))-q\left(1+r_{i}\right)\right]-t x_{i}^{\gamma}
\end{aligned}
$$

where $x_{i}^{\{.\}}$stands for the distance between a borrower of type $\{$.$\} and bank i$, and $x_{B}^{\{.\}}=1-x_{A}^{\{.\}}$. The payoff to a bank of the given type is written as:

$$
\begin{aligned}
& V_{i}^{\kappa}=D_{i}\left[\begin{array}{l}
\xi\left(\left(1+r_{i}\right)(\alpha+\gamma(1-\sigma)(q+\lambda(1-q)))+\left(1+r_{0}\right)(\beta+\gamma) \sigma\right) \\
+(1-\xi)\left(p_{\kappa}\left(1+r_{i}\right)(\alpha+(q+(1-q) \lambda) \gamma)+\left(1-p_{\kappa}\right)\left[1+r_{0}\right]\right)
\end{array}\right] \\
& V_{i}^{1-\kappa}=D_{i}\left[p_{1-\kappa}\left(1+r_{i}\right)(\alpha+(q+(1-q) \lambda) \gamma)+\left(1-p_{1-\kappa}\right)\left[1+r_{0}\right]\right]
\end{aligned}
$$


where $D_{i}$ is the demand for bank i loan contracts. LDE is defined as an equilibrium with $q^{*}=1, \xi^{*}=1$ and $p_{1-\kappa}^{*}=1$. For $q^{*}=1$, we check that a $\gamma$-type borrower will not want to deviate by choosing $q=0$ when $\xi^{*}=1$ and $p_{1-\kappa}^{*}=1$ :

$U_{i}^{\gamma}\left(q=1 \mid \xi=1, p_{1-\kappa}=1\right) \geq U_{i}^{\gamma}\left(q=0 \mid \xi=1, p_{1-\kappa}=1\right)$

This implies:

$(1-\kappa \sigma)\left(\mathrm{R}-r_{i}\right)-t x_{i}^{\gamma} \geq(1-\kappa \sigma)(1-\lambda)(1+R)-t x_{i}^{\gamma}$

$\lambda \geq \frac{1+r_{i}}{1+R}=\bar{\lambda}$

where $\bar{\lambda}$ is the LDE boundary value for $\lambda$ in Proposition 1 and equation (1) of the main text. A competent bank will choose $\xi^{*}=1$ when $V_{i}^{\kappa}\left(\xi=1 \mid q^{*}=1, p_{1-\kappa}^{*}\right) \geq$ $V_{i}^{\kappa}\left(\xi=0 \mid q^{*}=1, p_{\kappa}^{*}\right)$. This implies:

$\beta \geq \frac{\left(r_{i}-r_{0}\right) \gamma}{1+r_{0}}=\bar{\beta}$

where $\bar{\beta}$ is the boundary value for $\beta$ in Proposition 1 of the main text. In order to find the equilibrium value of $r_{i}$, write the total demand for bank $i$ loan contracts as: 
$D_{i}=\alpha D_{i}^{\alpha}+\beta D_{i}^{\beta}+\gamma D_{i}^{\gamma}$

i.e. the sum of total demand per type of borrower. These levels of demand are determined by the marginal borrower of each type. In equilibrium, each type of marginal borrower is indifferent between going to bank $A$ or bank $B$ for a loan. For the marginal honest borrower this gives:

$$
x_{A}^{\alpha}=\frac{1}{2}-\frac{r_{A}-r_{B}}{2 t}
$$

Similarly, the condition for the marginal opportunistic borrower is given by:

$$
x_{A}^{\gamma}=\frac{1}{2}-\frac{r_{A}-r_{B}}{2 t}(1-\kappa \sigma)
$$

If the marginal dishonest borrower is located exactly in the middle of the interval between the two banks has a non-negative payoff, then every dishonest borrower will apply to the nearest bank. This translates into:

$x_{A}^{\beta}=\frac{1}{2} \quad$ when $\quad \kappa \sigma \geq 1-\frac{t}{2}$

Collecting the terms and making the required assumptions, we have:

$$
D_{A}=\frac{1}{2}\left[1-\frac{(\alpha+(1-\kappa \sigma) \gamma)\left(r_{A}-r_{B}\right)}{t}\right]
$$


Substituting this into competent bank's payoff and solving the first order condition for a symmetric solution $\left(r_{A}=r_{B}\right)$, it can be checked that:

$$
1+r_{i}=1+r_{A}^{*}=1+r_{B}^{*}=\frac{t}{\alpha+(1-\kappa \sigma) \gamma}-\frac{(\beta+\gamma)\left(1+r_{0}\right) \sigma}{\alpha+(1-\sigma) \gamma}
$$

which appears as equation (2) of the main text. To ensure that all opportunistic borrowers apply for a loan (i.e. that the marginal opportunistic borrower is located in the middle of the interval), it is sufficient to assume that $t \leq(1-\alpha)\left(1+r_{0}\right) \sigma=\bar{t}$, where $\bar{t}$ is the boundary value for $t$ in Proposition 1 of the main text. Note that when the participation constraint of the marginal opportunistic borrower is satisfied, so also will be the participation constraint of the marginal honest borrower (because the expected payoff for an honest borrower in LDE is higher than the payoff for an opportunistic borrower located at the same point). The stricter of the two conditions on $t$ will ensure that borrowers of every type apply. To solve for HDE with $q^{*}=0, \xi=1$ and $p_{1-\kappa}=1$, repeat the steps of the solution for LDE. Opportunistic borrowers chose $q^{*}=0$ when the reverse of (A8) holds. The competent type of bank still prefers to screen all its loan applications if (A9) holds. Additionally, in this case, given that $q^{*}=$ 0 , the competent bank prefers screening and lending to those with an untainted record over not screening and not lending to any borrower: $V_{i}^{\kappa}\left(\xi^{*}=1 \mid q^{*}=1\right) \quad \geq$ $V_{i}^{\kappa}\left(\xi=0, p_{\kappa}=0 \mid q^{*}=0\right)$. This implies:

$$
\lambda \geq\left[\frac{(1-(1-\alpha) \sigma)\left(1+r_{0}\right)}{\left(1+r_{A}\right)}-\alpha\right]\left[\frac{1}{(1-\sigma) \gamma}\right]=\underline{\lambda}
$$


where $\underline{\lambda}$ is the HDE boundary value for $\lambda$ in Proposition 1 of the main text. Since opportunistic borrowers do not repay their loans in HDE, their expected payoff no longer depends on $r_{i}$ and therefore the marginal borrowers of each type in HDE are given by (A11), (A13) and:

$x_{A}^{\gamma}=\frac{1}{2}$ when $(1-\kappa \sigma)\left(R-r_{A}\right) \geq \frac{t}{2}$

Solving for $r_{A}$ from the first order condition of the expected payoff maximisation of the competent bank and assuming a symmetric solution, the equilibrium rate in HDE is:

$1+r_{i}=1+r_{A}^{*}=1+r_{B}^{*}=\frac{2 t}{\alpha}-\frac{(1-\alpha)\left(1+r_{0}\right) \sigma}{\alpha+(1-\sigma) \gamma \lambda}$

To complete the proposition, NLE obtains when the competent bank finds it more profitable to invest the loanable funds into the safe asset rather than to make loans: $V_{i}^{\kappa}\left(\xi^{*}=1 \mid q^{*}=1\right)<V_{i}^{\kappa}\left(\xi=0, p_{\kappa}=0 \mid q^{*}=0\right)$, which is the reverse of (A16). 